EL CAZADOR HUMANO. UNA VISIÓN ANTROPOLÓGICA, SOCIOLÓGICA Y ECOLÓGICA / THE HUMAN HUNTER. AN ANTHROPOLOGICAL, SOCIOLOGICAL AND ECOLOGICAL APPROACH

\section{LA CAZA EN EL PALEOLÍTICO SUPERIOR: NOCIONES CLAVES DE LA ANTROPOLOGÍA ECONÓMICA APLICADA A LA PENÍNSULA IBÉRICA}

\author{
José Manuel Quesada López \\ Universidad Nacional de Educación a Distancia \\ ORCID iD: http://orcid.org/0000-0002-3281-3052 \\ jmquesada@geo.uned.es
}

Cómo citar este artículo/Citation: Quesada López, J. M. (2017). La caza en el Paleolítico Superior: nociones claves de la antropología económica aplicada a la Península Ibérica. Arbor, 193 (786): a412. doi: http://dx.doi.org/10.3989/arbor.2017.786n4001

Recibido: 30 abril 2015. Aceptado: 04 febrero 2016.

RESUMEN: Las investigaciones paleoeconómicas realizadas los últimos años sobre la caza en el Paleolítico Superior de la Península Ibérica habrían sido incomprensibles sin la relevante participación de la Escuela de Antropología americana. Este artículo resume la historia de aquellas investigaciones, los principales hitos que marcaron la evolución de las estrategias de caza y el contexto teórico de las principales hipótesis.

PALABRAS CLAVE: Caza; paleoeconomía; Paleolítico Superior; Península Ibérica.

\section{HUNTING IN THE UPPER PALEOLITHIC: KEY CONCEPTS OF ECONOMIC ANTHROPOLOGY APPLIED TO THE IBERIAN PENINSULA}

Copyright: (C) 2017 CSIC. Este es un artículo de acceso abierto distribuido bajo los términos de la licencia Creative Commons Attribution (CC BY) España 3.0.

ABSTRACT: Paleoeconomic research carried out in recent years into Upper Palaeolithic hunting in the Iberian Peninsula would have been impossible without the important contribution of the American Anthropology School. This paper summarizes the history of this research, and the main landmarks in the evolution of hunting strategies and the theoretical context of the principal hypotheses.

KEYWORDS: Hunting; Iberian region; paleoeconomy; Upper Palaeolithic. 


\section{INTRODUCCIÓN}

Hasta los primeros años setenta poco se conocía de los modos de subsistencia de las comunidades humanas que poblaron la Península Ibérica durante los treinta mil años del Paleolítico Superior. El punto de partida fue la tesis doctoral publicada por el paleontólogo vasco Jesús Altuna acerca de las faunas cantábricas (Altuna, 1972), que no tardó en convertirse en la referencia principal para las futuras investigaciones que surgieron en materia de arqueozoología, paleoeconomía y paleoambiente. El entonces joven paleontólogo intuyó por primera vez la relevancia del ciervo en los modos de subsistencia del Paleolítico Superior Cantábrico, su protagonismo principal como presa preferida en las actividades de caza y su contribución esencial en la dieta humana.

Las investigaciones emprendidas a partir de entonces revalidaron el alcance del ciervo en la vida de las poblaciones humanas que habitaron la Península Ibérica en el Paleolítico Superior. En cierta manera aqueIla especie tuvo un protagonismo similar al registrado para el reno en las llanuras abiertas del sudoeste de Francia; y al señalado para bisontes, bóvidos y caballos en las severas estepas de la Europa central y oriental. El rol prioritario del ciervo en la Península Ibérica resultó consecuente con unas características biogeográficas particularmente propicias para una proliferación generalizada de la especie: la latitud meridional peninsular, la templanza climática respecto a franjas europeas más septentrionales, el potencial de las fachadas costeras, la regeneración del nivel de productividad ecológica y la notable diversidad ecosistémica a nivel regional, convirtieron nuestra Península Ibérica en solar idóneo para la propagación de los rebaños de ciervo, sobre todo en los estrechos corredores costeros.

La caza del ciervo se completaba con otros dos escenarios de caza: las cacerías habituales de cápridos que menudeaban por las abruptas laderas montañosas; y las matanzas de caballo, bóvido y bisonte que pastaban entre prados y herbazales de las planicies y llanuras litorales. En las amplias mesetas interiores, influenciadas por unas condiciones climáticas más rigurosas y extremas, las cacerías de équidos y bóvidos podrían haber adquirido particular relevancia, aunque a ciencia cierta no hay datos al respecto. En cualquier caso, las prácticas de caza paleolíticas de las comunidades peninsulares se dirigieron principalmente a los cinco animales citados. A partir de la base común formada por este repertorio de especies se sucedieron los modelos de comportamiento cinegéticos (especialización/diversificación, collector/forager) y los patrones de caza (grado de estacionalidad, intensidad de las capturas, selección de las presas, preferencias por edad/sexo) que han protagonizado los modos de vida de nuestros antepasados sapiens de la Península Ibérica.

\section{EL PALEOLÍTICO SUPERIOR INICIAL: EL CAZADOR OPORTUNISTA}

Hace 40.000 años se produjo la aparición del Homo sapiens en la Península Ibérica, la especie que representó la implantación del comportamiento plenamente moderno. Pero durante los primeros veinte mil años de vida de nuestra especie por las tierras peninsulares hay pocas certezas sobre los modos de vida de las bandas cazadoras-recolectoras. Más bien cabría decir que las supuestas evidencias se limitan a conjeturas inferidas a partir de informaciones precarias y fragmentarias, interpretadas por lo habitual a través estereotipos controvertidos de problemática. La imagen estándar de aquellas comunidades remite a bandas de cazadores-recolectores integradas por un parco puñado de individuos, habituadas a costumbres nómadas continuas, inquietas por buscar alimento de manera incesante por amplios territorios.

La mayoría de los prehistoriadores han caracterizado los modos de caza de los primeros sapiens que habitaron la Península a partir de estas premisas: un patrón generalista en la selección de presas mediante la captura de un amplio elenco de animales; una estrategia de carácter oportunista ajena a un sistema de planificación logística; y un comportamiento táctico aleatorio en la búsqueda de las presas, basado en encuentros fortuitos y aleatorios. De este modo la caza representaría una proyección más o menos directa de los recursos locales (riqueza, abundancia y densidad de presas), con un impacto reducido en la naturaleza, supeditada a costes elevados en el plano de la movilidad residencial pero con una reducida inversión en cuanto a la movilidad logística. Esta imagen se ajusta bastante bien al modelo evolucionista que asocia los primeros humanos modernos con sistemas de caza rudimentarios, acomodando las necesidades a las posibilidades del entorno y padeciendo los riesgos que los vaivenes de la naturaleza generarían de modo casi inevitable en nuestras latitudes. Siguiendo esta línea de pensamiento, algunos especialistas han formulado incluso semejanzas entre las actividades cinegéticas de los primeros sapiens y los hábitos de caza de los últimos neandertales (RasiIla Vives y Straus, 2004), una propuesta que llevada a sus últimas implicaciones trasciende la simple escena cinegética para conectar con la controversia sobre los orígenes del comportamiento moderno. 


\section{EL SOLUTRENSE Y MAGDALENIENSE: LA CAZA ESPECIALIZADA}

La tesis doctoral que publicó Altuna a inicios de los setenta proporcionó una información paleontológica aceptable para iniciar los estudios sobre las prácticas de caza del Paleolítico Superior peninsular. La primera aportación arqueozoológica se debió al antropólogo estadounidense Leslie G. Freeman, que realizó el primer estudio sobre la evolución de los modos de subsistencia a lo largo del Paleolítico cantábrico (Freeman, 1973), inusual trabajo de impronta paleoeconómica influenciado por las premisas teóricas procedentes de la Antropología americana y particularmente representativo de la Escuela procesualista de Chicago. Freeman recurrió a una metodología innovadora para abordar la precaria información cantábrica disponible por entonces y para proporcionar una interpretación ajustada a los entonces sorprendentes datos registrados en una cueva cántabra conocida como El Juyo. Los niveles magdalenienses depositados en esta cueva hace 15.000 años presentaban una acumulación tan ingente de huesos de ciervo que Freeman recapacitó sobre una interesante hipótesis: la posibilidad de que los cazadores hubieran adoptado en el período magdaleniense una estrategia cinegética profundamente alejada del modelo oportunista, una estrategia de caza especializada del ciervo.
En opinión de Freeman la caza sistemática del ciervo magdaleniense representó un mecanismo de «especialización territorial» para incrementar la cantidad de alimento. En realidad el concepto «especialización territorial» había sido concebido por Kent V. Flannery, prestigioso arqueólogo del Próximo Oriente que había impulsado un innovador proyecto de investigación acerca de la transición al modo de producción de alimentos en el Creciente Fértil. En opinión de Flannery la especialización territorial había representado una estrategia oportuna para aumentar el volumen de alimento, recurriendo a una utilización progresivamente intensificada de recursos procedentes de situaciones cada vez más localizadas, una estrategia planificada que a la larga produjo una tendencia progresiva de sustitución del modo de subsistencia cazador-recolector por el modo de producción agrícola y ganadero. Freeman proyectó el concepto especialización territorial al mundo cazador-recolector magdaleniense, pero su aplicación tuvo inmediata repercusión como punto de partida de una larga polémica historiográfica que a día de hoy permanece abierta. Por de pronto, tan solo un par de años más tarde de la publicación de Freeman, un joven doctorando estadounidense asumió el testigo de la hipótesis especializada pero aportando un modelo de comportamiento cinegético mucho más complejo y a la par controvertido.

Figura 1. La caza especializada del ciervo se relaciona con tácticas planificadas, destinadas a interceptar los animales en lugares estratégicos, un modo de comportamiento típico de los collectores. En la imagen, una partida de cazadores analiza el valor estratégico de un valle cerrado para la emboscada de animales.

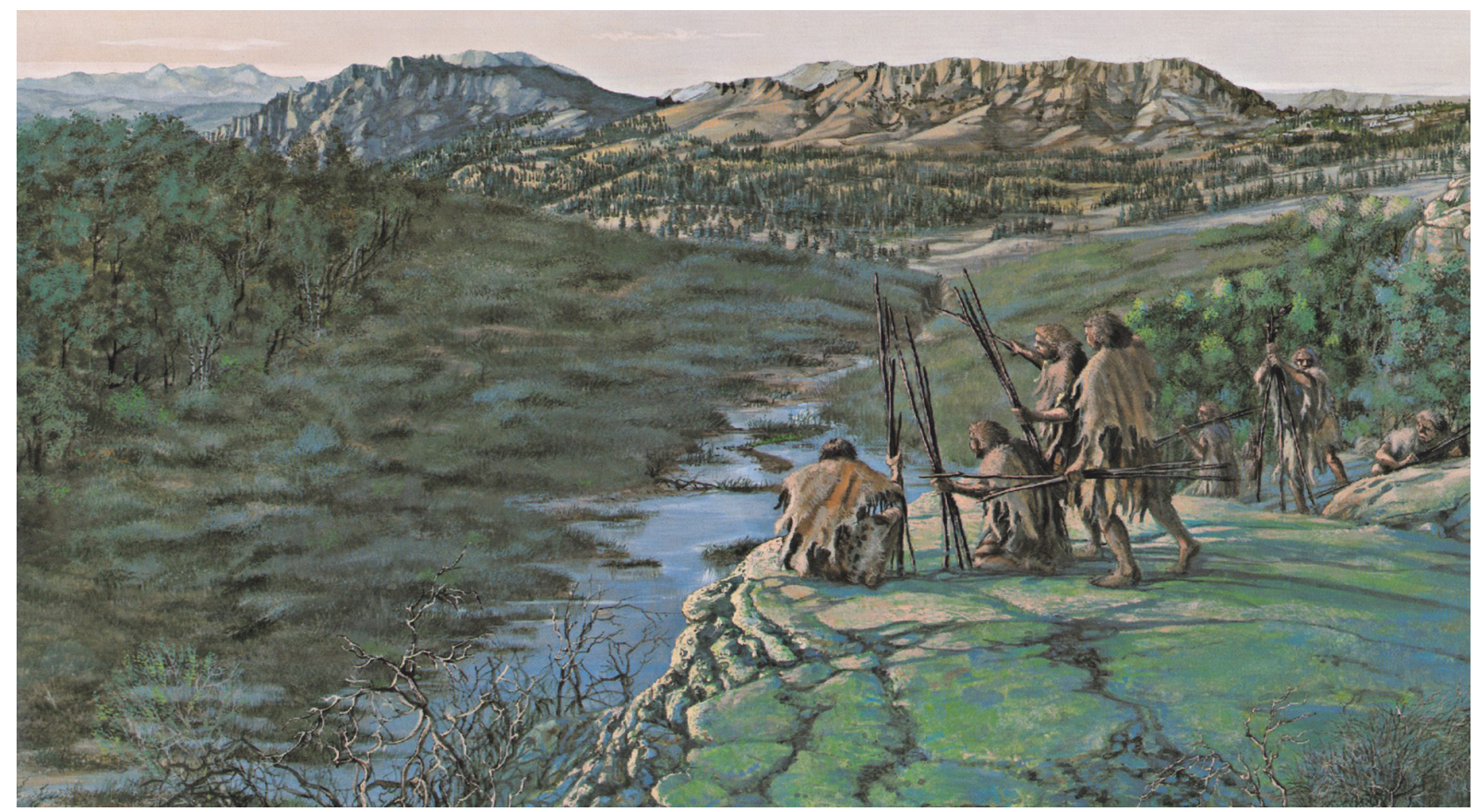


Fue a mediados de los setenta cuando el prehistoriador americano Lawrence G. Straus intervino decisivamente en el debate sobre la caza especializada con su proyecto doctoral sobre el Solutrense vasco-cantábrico, primera revisión moderna para este período crucial del Paleolítico Superior (Straus, 1977). Esta tesis doctoral influyó decisivamente en la renovación teórica de la investigación paleolítica de nuestro país pues supuso la resuelta incorporación de la tradición de la Antropología económica americana, materializada a través de la corriente Ilamada Arqueología procesual, la escuela de pensamiento liderada audazmente por el célebre antropólogo Lewis R. Binford desde finales de los años sesenta. En su conocido axioma la cultura es un medio de adaptación extrasomático del hombre, Binford defendió con absoluta determinación la aquiescencia del procesualismo con los principios del materialismo cultural de raigambre determinista. Desde la adhesión incondicional a tales principios, Straus facultó una nueva imagen sobre el Paleolítico Superior, donde la economía saltaba a primer plano, los modos de subsistencia pasaban a ocupar un lugar preminente en la caracterización cultural y las prácticas de caza se concebían como una muestra inmediata de la adaptación cultural y un reflejo directo del progreso de la humanidad. El estudio de los restos faunísticos solutrenses dispersos entre los museos cantábricos y los fructíferos resultados registrados en las excavaciones en la cueva asturiana de La Riera permitieron a Straus componer un escenario cinegético más complejo que el proyectado por Freeman años antes, basado en tres puntos básicos:

1. La implantación de la caza especializada solutrense. La primera premisa consistió en adelantar el momento de implantación de la caza especializada varios miles de años antes de lo propuesto por Freeman. En opinión de Straus la caza sistemática del ciervo se había iniciado en el período solutrense, coincidiendo grosso modo con el ciclo climático crítico llamado Último Máximo Glacial, período caracterizado por un intenso desarrollo de los glaciares y un agudo enfriamiento climático. La implantación de la especialización en un período sumamente crítico, mediatizado por una importante reducción de la productividad ecológica y por una restricción de las posibilidades ambientales, resulta aparentemente contradictorio pero bien podría ponerse en relación con la capacidad de las comunidades humanas solutrenses para superar profundas adversidades paleoambientales en un ejercicio de resiliencia.

2. La incorporación de tácticas de caza masiva. La segunda premisa resultaba bastante más controver- tida porque sostenía que la caza especializada del ciervo ocultaba realmente la implantación de una novedad táctica de primer orden: la matanza masiva de los rebaños mediante batidas planificadas de manera minuciosa a fin de masacrar el mayor número posible de animales. La hipótesis de la matanza catastrófica no era novedosa para el Paleolítico pues ya había sido planteada para tierras francesas y centroeuropeas tanto en la caza de renos como de caballos. Los antropólogos americanos conocían perfectamente las matanzas catastróficas a través de imágenes etnohistóricas del Nuevo Continente, en concreto a través de las emboscadas de los rebaños de ciervos ejecutadas por los nativos amerindios de las costas noroccidentales y las matanzas de manadas de caribúes perpetradas por los nunamiut de las latitudes subárticas canadienses. Fueron precisamente estas imágenes etnográficas las que sirvieron a Straus para determinar las posibles variantes tácticas de la caza masiva de ciervos en el Solutrense cantábrico (Straus, 1983): la batida mediante celadas de los rebaños en valles ciegos y encajonados de difícil salida; la cacería invernal de animales mediante la conducción de los rebaños a zonas dificultosas cubiertas de nieve; y las emboscas en lugares de paso de carácter estratégico como desfiladeros o vados, instalados en las rutas migratorias estacionales que conectan los pastos altos de verano y los pastos bajos de invierno.

3. La movilidad logística estacional. La tercera premisa se refería a una precisa planificación territorial de las prácticas de caza mediante una triple combinación: la reducción de la movilidad residencial, el aumento de la movilidad logística y la regulación estacional de los movimientos. De acuerdo con las ideas anteriores las poblaciones solutrenses y magdalenienses renunciaron a los hábitos nómadas de sus predecesores del Paleolítico Superior inicial (importunados por un desplazamiento continuo del campamento residencial) y adoptaron unas rutinas más sedentarias al prolongar las ocupaciones residenciales durante largas temporadas del año. La reducción de la movilidad residencial tuvo una contrapartida inevitable: un incremento de la movilidad logística basada en traslados de pequeñas partidas de cazadores hasta lugares estratégicos que servían como cazaderos más o menos especializados. Los desplazamientos logísticos hasta los cazaderos situados tierra adentro se realizarían de manera periódica con una cadencia estacional, condicionada por los diferentes ritmos de productividad de cada entorno. 
Figura 2. La caza masiva del ciervo se basó sobre todo en la emboscada de los rebaños formados por las hembras y sus crías (Straus, 1983). En la imagen, ciervas pintadas de la cueva de Covalanas (Santander).

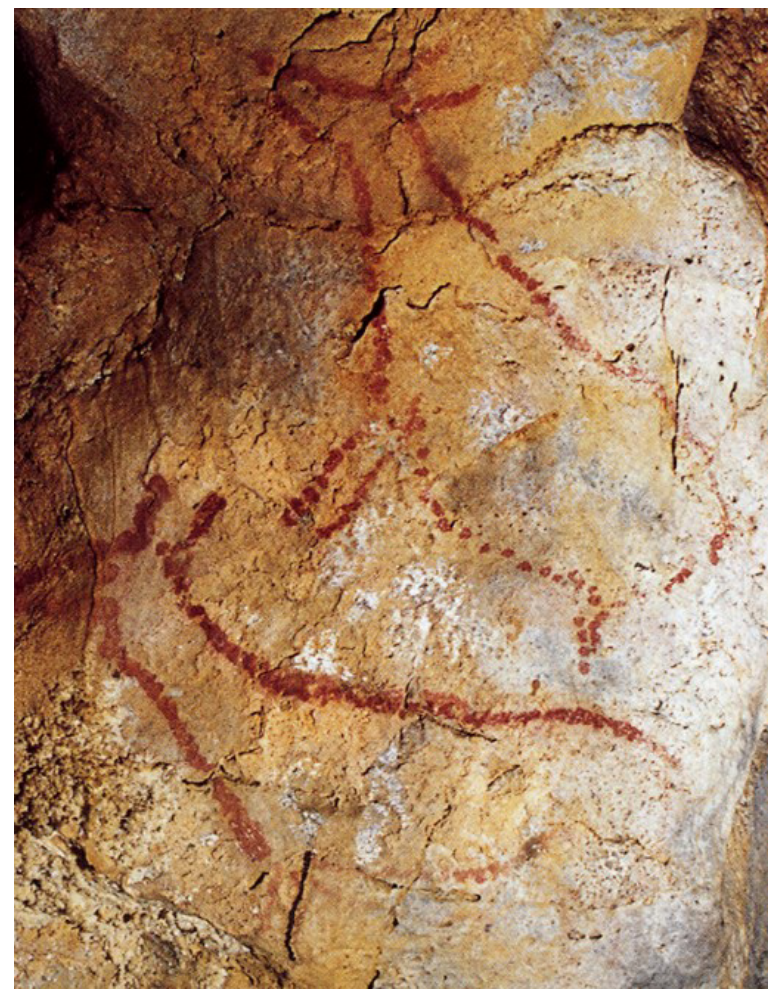

Los campamentos residenciales se habrían emplazado a lo largo de las planicies litorales, cuyas praderías y pastizales habrían propiciado el ojeo individualizado de los herbívoros mayores (caballos, bóvidos, bisontes) y el rastreo masivo de los rebaños de ciervo que proliferaban por las llanuras y los bosques. Por su parte, los cazaderos logísticos se habrían apostado en zonas estratégicas de los valles interiores y en las laderas montuosas circundantes, próximos a las vertientes rocosas tan apropiadas para la cabra y a los refugios arbolados apreciados por el rebeco. De esta manera la complementariedad logística de la caza planificada desde los campamentos residenciales y los cazaderos logísticos permitía un aprovechamiento sistemático local de las posibilidades medioambientales y sumaba una nueva dimensión al concepto de especialización territorial de Freeman.

La idea de que los cazadores tardiglaciares recurrieron a la movilidad logística estacional ente las planicies costeras y las montañas prelitorales resultó lo bastante convincente como para aplicarse a otras regiones de la periferia peninsular. El estadounidense lain Davidson aseguró que las comunidades solutrenses/magdalenienses que poblaron el litoral levantino recurrían a movimientos de la costa a la montaña para aprovechar las posibilidades del territorio (Davidson, 1989). Pero también ha sido utilizado por varios especialistas para describir los patrones de vida de las comunidades cazadoras-recolectoras tardiglaciares que habitaron la larga fachada andaluza, ya fuera Almería, Málaga o Cádiz (Ramos, 1999).

\section{¿QUÉ HABÍA DETRÁS DE LA CAZA? O CÓMO ALIMENTAR A LA GENTE Y SOBREVIVIR A LAS INCLEMENCIAS DEL CLIMA}

La caza especializada de los rebaños de ciervos propuesta por Freeman y Straus se ajustaba bastante bien al modelo de comportamiento que Binford calificó como collector en la prestigiosa revista American Antiquity (Binford, 1980). En su opinión el proceder collector resultaba propio de aquellos grupos cazadores-recolectores que practicaban un modus vivendi relativamente complejo caracterizado varios rasgos: la planificación meticulosa de las actividades de subsistencia, la búsqueda intencionada de recursos, la voluntad de usar tácticas para "interceptar" las presas, la adaptabilidad a las posibilidades más oportunas del entorno y la perseverancia en minimizar las contingencias inherentes al modo de vida oportunista.

La aplicación de la expresión collector a los grupos solutrenses y magdalenienses peninsulares no tardó en trascender a la producción científica de nuestro país. Pero su aplicación acarreó un coste teórico insoslayable porque hubo que asumir ad hoc los condicionamientos inherentes al modelo ideado por Binford, profundamente arraigados en el determinismo ambiental. Los collectores representaban un modo de vida adaptado específicamente a aquellos entornos ecológicos supeditados a un plantel de recursos limitado, relativamente disperso pero proclive a concentraciones puntuales, breves y de carácter estacional. Fue de esa manera como la discusión sobre la caza acabó implicada en debates ambientales y como tuvo lugar la incorporación de la Ecología Cultural a la investigación del Paleolítico Superior peninsular.

La Ecología Cultural irrumpió en la discusión sobre la caza solutrense y magdaleniense, aportando su robusto corpus teórico, con los trabajos redactados por Karl W. Butzer al finalizar los ochenta. El ecólogo americano concretó los parámetros teóricos necesarios para la implantación de las prácticas de movilidad pulsatoria o pendular, basadas en los ritmos estacionales 
Figura 3. La caza masiva se completó probablemente con las cacerías de ciervos durante la época de celo otoñal (Straus, 1983). En la imagen, grabado de ciervo alanceado de la cueva de Peña de Candamo (Asturias).

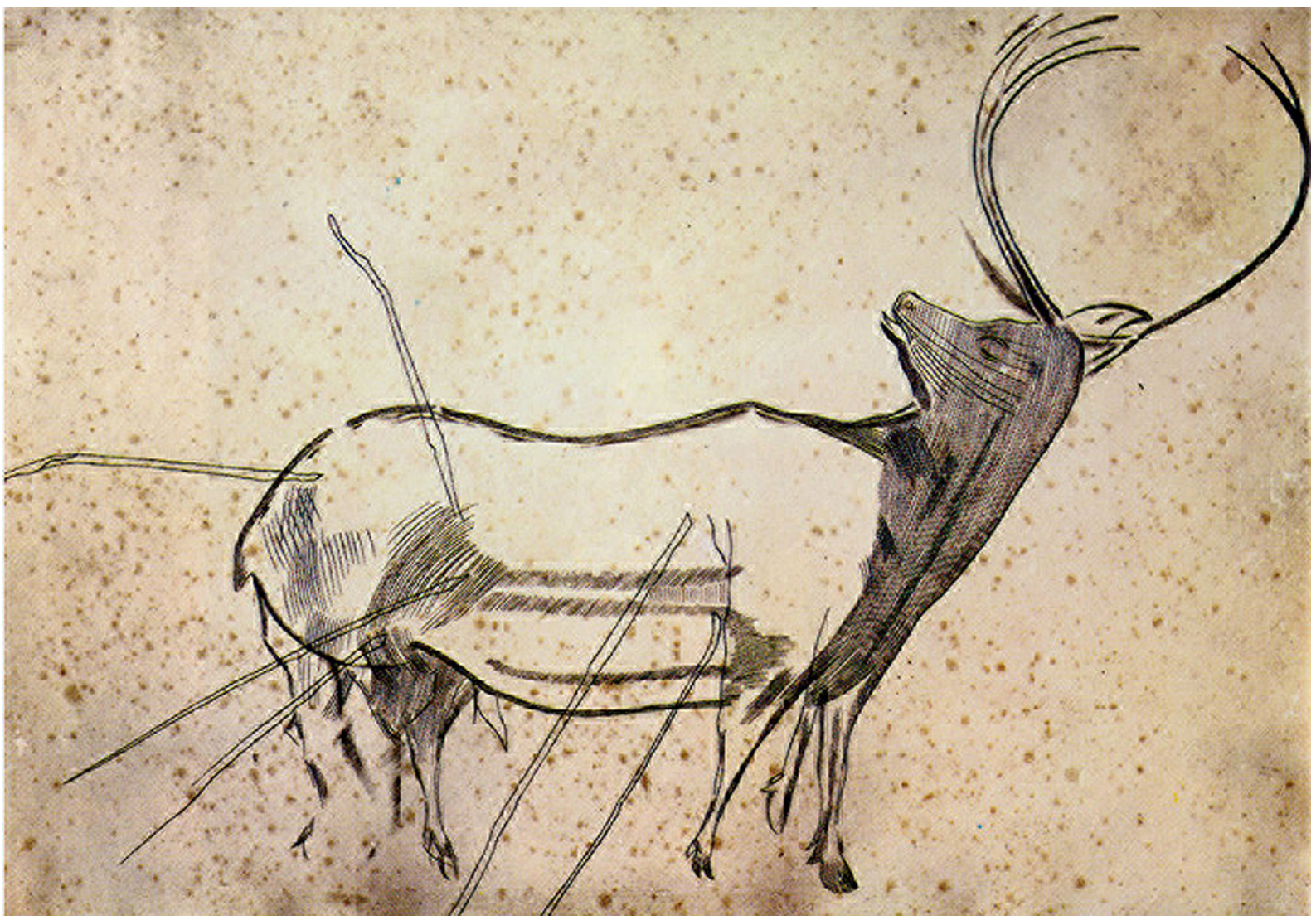

(Butzer, 1989). En su opinión los movimientos logísticos entre ecosistemas variados podían interpretarse desde dos perspectivas. Por una parte representaban adaptaciones específicas a aquellos medioambientes sometidos a crisis periódicas, situaciones cíclicas de estrés tanto en la abundancia como la densidad de los recursos. Por otra parte, representaban estrategias para optimizar los recursos de un territorio y solventar oportunamente las fluctuaciones de los recursos, acomodando las necesidades humanas a las variaciones que influyen en la abundancia, densidad y distribución temporal de las presas. Estas propuestas participaban de una mentalidad economicista propia de una de las líneas de investigación más conocidas de la Ecología Cultural: la Teoría de Forrajeo Óptimo ${ }^{1}$.

Fue el prehistoriador estadounidense Geoffrey A. Clark, a la sazón codirector junto a Straus de las excavaciones en la cueva de La Riera, el mejor representante de la Teoría del Forrajeo Óptimo en la investigación paleolítica de nuestro país. Recurriendo a la metodología propia de la Amplitud de Nicho, Clark formuló una ambiciosa hipótesis acerca de la evolución de la subsistencia cantábrica desde el Paleolítico inferior hasta los tiempos históricos (Clark y Yi, 1983). Su trabajo fue un contrapunto interesante al enfoque de Straus, preocupado por buscar una explicación empírica a los datos paleontológicos de campo. La labor de Clark prometía más bien una interpretación sistémica de los cambios paleoeconómicos acaecidos durante miles de años, la manera de proceder típica de los arqueólogos procesuales, a la sazón fascinados por los procesos de cambio adaptativo a largo plazo. En su hipótesis se incluía un precepto crucial de la adaptación paleolítica: la caza y otras prácticas de explotación de recursos representaron, por encima de todo, mecanismos para la intensificación alimentaria a fin de cubrir las necesidades nutricionales de una población cazadora-recolectora abrumada por un incremento perpetuo de la población. Esta tesis recogía las premisas del modelo neomalthusiano programado por la conocida Teoría de la presión demográfica, que el prehistoriador Mark Nathan Cohen había revitali- 
Figura 4. El arte post-paleolítico levantino nos ha legado imágenes muy plásticas para presumir como pudieron ser las batidas catastróficas de los rebaños de cérvidos. En la imagen, escena de caza pintada en el Barranco de la Valltorta (Castellón).

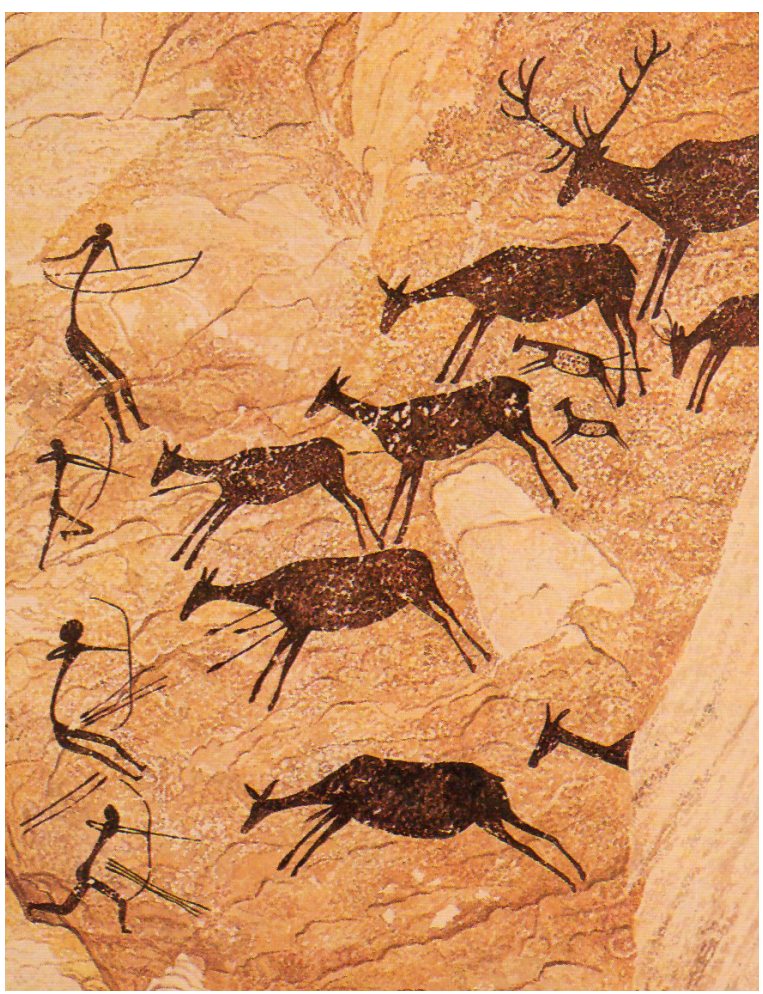

zado por entonces en un libro que alcanzó notable impacto, bajo un título tan significativo como La crisis alimentaria de la prehistoria ${ }^{2}$ (Cohen, 1981).

En opinión de Clark, la caza había soportado un largo proceso de intensificación alimentaria durante gran parte del Paleolítico a fin de cubrir las necesidades incesantes de una población en crecimiento. La sustitución de la caza oportunista que practicaban los primeros sapiens por la caza especializada solutrense y magdaleniense constituyó uno de los mecanismos necesarios para incrementar el volumen de alimento. Pero las batidas catastróficas especializadas representaron el cenit de las posibilidades de intensificación cinegética, provocando un agotamiento del potencial implícito en la caza para mantener las continuas demandas nutricionales. Fue así como las comunidades humanas utilizaron prácticas de consumo alternativas para proseguir la incesante exigencia de presión alimentaria, procurando aumentar las labores de pesca, recolección vegetal y marisqueo. En este último escenario la caza se mantuvo como una estrategia equili- brada y mantuvo su contribución principal como pilar estable de la alimentación hasta los últimos momentos del Paleolítico, coincidiendo con las primeras manifestaciones climáticas claras del Postglaciar.

Los cambios acaecidos en las prácticas de caza hacia el inicio postglaciar de hace 11.000 años permiten apreciar las bases de un modelo alternativo al propuesto por Clark bajo las premisas de la presión demográfica. Finalizaban los años ochenta cuando varios prehistoriadores utilizaron planteamientos ambientalistas para interpretar los cambios culturales postglaciares y justificar los cambios que dieron por tierra con la estabilidad cinegética instalada tras la adopción de la caza especializada. El inspirador principal de la Teoría Ambiental fue el prehistoriador anglosajón Geoffrey N. Bailey, involucrado con la tradición paleoambiental de Cambridge. Bailey consideró que la compleja cadena de modificaciones ecológicas había sido la causa principal del cambio que operó en las conductas cazadoras al iniciar el Holoceno. La inundación de las plataformas litorales redujo notablemente los territorios costeros, provocando la disminución de las especies de pradera y reduciendo las posibilidades de caza de équidos y bóvidos. El calentamiento y las lluvias provocaron la colonización boscosa adecuada para la proliferación de animales propios de ambientes templados arbolados, permitiendo nuevas oportunidades para cazar corzos, rebecos y jabalíes. Pero este cambio ambiental no solo generó modificaciones en cuanto a la abundancia, densidad y distribución de los animales; también trascendió a los hábitos territoriales, rutinas estacionales y composiciones de los rebaños, repercutiendo en los modos de caza de manera más que significativa (Quesada, 1998a).

\section{CONCLUSIONES}

En todas las propuestas señaladas se mantiene como pilar central un axioma trascendental del procesualismo: la adaptación como mecanismo necesario para superar los desafíos que continuamente surgen en la historia de la humanidad. Pero paradójicamente la mayoría de los antropólogos económicos que configuran la primera generación procesualista de los estudios paleolíticos peninsulares transmitieron en sus trabajos una imagen más bien estática sobre la caza del Paleolítico Superior. En todos ellos hay una tendencia a considerar que una vez implantado el patrón cinegético especializado, la caza se convirtió en una estrategia estable y en un pilar invariable de la dieta de las comunidades humanas durante miles de años, hasta que acontecieron los cambios culturales en el tránsito entre el Pleistoceno y el Holoceno. 
Figura 5. La Teoría de la presión demográfica ha influido sobremanera en las interpretaciones sobre los modos de adaptación de las prácticas cinegéticas de los cazadores-recolectores peninsulares. La imagen presenta un modelo metodológico propio de la Arqueología procesual, ideado por D. R. Harris (1978) para explicar las relaciones adaptativas que mediaron entre el modo cazador-recolector y el productor, sobre la base de la Teoría de la presión demográfica.

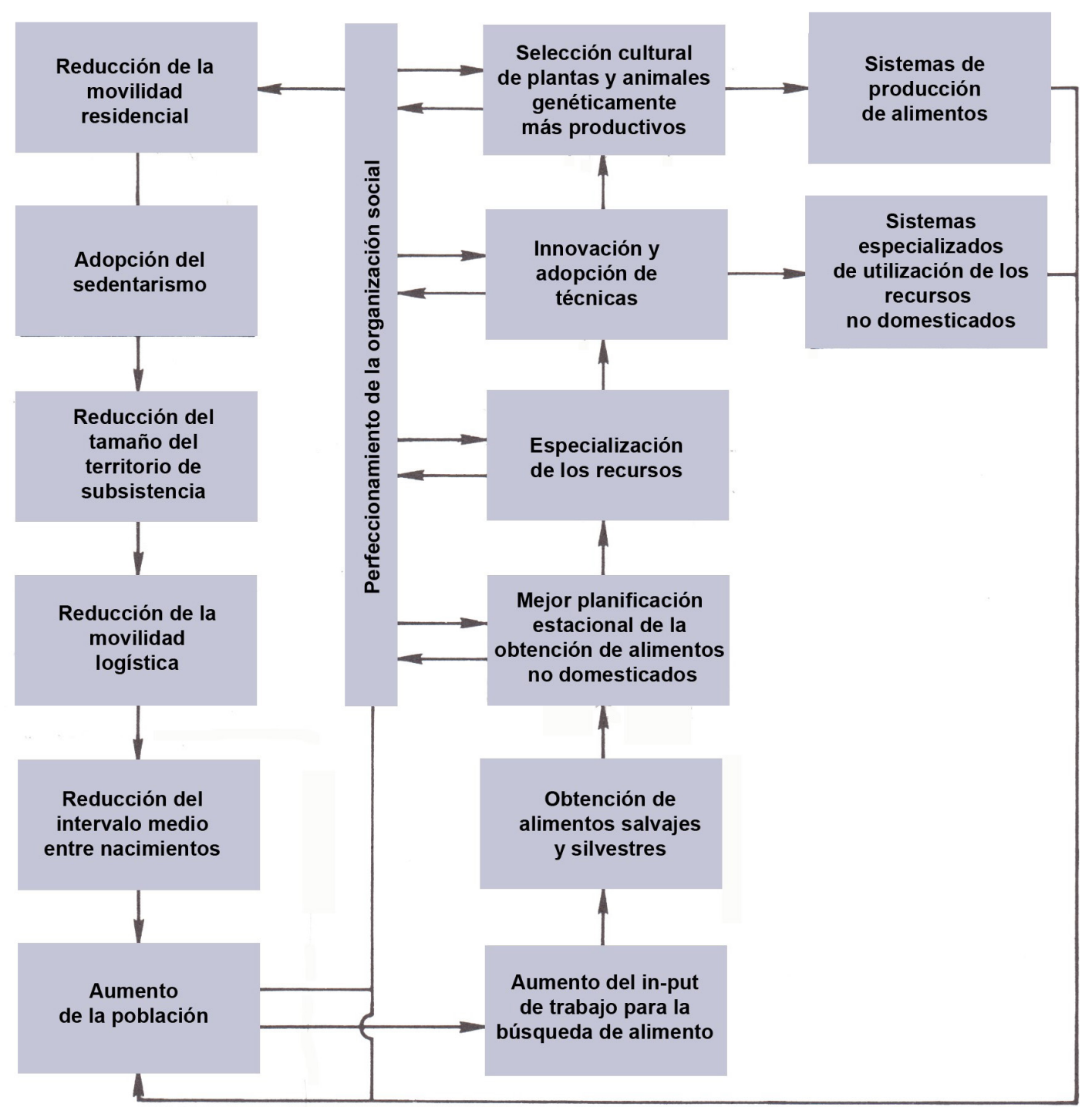

Hubo que esperar hasta los noventa para que surgieran las primeras hipótesis interesadas por los procesos de cambio a medio plazo, promovidas por una segunda generación procesualista, representada por prehistoriadores españoles. La tesis doctoral de César González Sainz fue el primer trabajo que avaló la capacidad de adaptación de las prácticas de caza magdalenienses cantábricas (González Sainz, 1989), en el momento particularmente crítico que se correspondía con el último recrudecimiento de la glaciación würmiense conocido entre los especialistas como Younger Dryas. Pero la ver- satilidad de los cazadores para adecuar las prácticas de caza a las necesidades y a las condiciones ambientales puede rastrearse mucho antes. Los cazadores solutrenses que padecieron la crisis del Último Máximo Glacial modificaron asiduamente las prácticas cinegéticas y recurrieron de manera sucesiva a tres modelos de caza distintos, para solventar este triple compromiso: afrontar el descenso de la productividad ambiental, optimizar las variantes ecológicas disponibles en el entorno y aumentar la producción para resolver las exigencias del incremento de la población (Quesada, 1998b). 
Las últimas tendencias procesualistas, integradas bajo la Teoría catastrofista, han acrecentado el interés por estos procesos de cambios repentinos, bruscos y coyunturales. El catastrofismo viene a ser contrapunto radical al antiguo marco de pensamiento procesualista de los setenta, que interpretaba los cambios culturales como procesos paulatinos a largo plazo pero nunca como crisis puntuales o revolucionarias. En esa línea de trabajo ha destacado el paleolitista catalán Jordi Estévez con sus reflexiones acerca del potencial de las crisis breves para catalizar los cambios en las prácticas de caza. En su opinión, el cambio que se produjo en la transición del Pleistoceno al Holoceno pudo significar el colapso del sistema de caza especializado en la caza del ciervo. No en vano un sistema especializado posee un riesgo muy elevado por su dependencia hacia unos pocos recursos, de manera que bastaría una crisis puntual provocada por un período corto de intensas y constantes nevadas para situar las poblaciones de un animal como el ciervo, so- metido a una continuada presión cinegética desde largo tiempo, en una situación crítica de retorno imposible y para provocar un fallo sistémico en todo el modo de subsistencia (Estévez, 2005).

En la actualidad las interpretaciones cinegéticas vinculadas con el Funcionalismo, la Ecología Cultural y el Procesualismo resultan menos ambiciosas que las ideadas por los representantes netos de la Antropología americana de los años setenta y ochenta. En función de los vaivenes historiográficos de las ciencias sociales, las aportaciones actuales respiran un mayor escepticismo, prudencia y preocupación por la historia a corto plazo. Pero incluso en las formulaciones más recientes de la Antropología económica, las propuestas teóricas desarrolladas por los prehistoriadores anglosajones de los años setenta y ochenta aún proporcionan un cuerpo teórico principal para reconstruir las conductas de caza y los modos de alimentación que permitieron la subsistencia de aquellos antiguos cazadores-recolectores.

\section{NOTAS}

1. Para una crítica a la versión economicista y actualista "capitalista" de sociedades pasadas se puede acudir a los argumentos de la Arqueología Social de Ramos (1999).

\section{BIBLIOGRAFÍA}

Altuna, J. (1972). Fauna de mamíferos de los yacimientos prehistóricos de Guipúzcoa. Con catálogo de los mamíferos cuaternarios del Cantábrico y del Pirineo Occidental. San Sebastián: Sociedad de Ciencias Naturales Aranzadi. Disponible en http://www.rhinoresourcecenter.com/ pdf_files/129/1293849734.pdf?view y en http://www.rhinoresourcecenter.com/ pdf_files/129/1293849925.pdf?view

Arias Cabal, P. (1991). De cazadores a campesinos. La transición al neolítico en la región cantábrica. Santander: Universidad de Cantabria / Asamblea Regional de Cantabria.

Binford, L. R. (1980). Willow Smoke and Dogs' Tails: Hunther-Gatherer Settlement Systems and Archaeological Site Formation. American Antiquity, 45 (1), pp. 4-20. https://doi. org/10.2307/279653

Butzer, K. W. (1989). Arqueología, una ecología del hombre. Método y teoría
2. Para apreciar los detalles de la Teoría de la presión demográfica en el caso cantábrico se puede consultar Arias Cabal (1991). rican Antiquity 38 (1), pp. 3-44. https:// doi.org/10.2307/279309

González Sainz, C. (1989). El Magdaleniense Superior Final de la región cantábrica. [Tesis doctoral inédita]. Universidad de Cantabria: Santander. Disponible en http://www.tdx.cat/bitstream/ handle/10803/22651/0de8.CGSprevio_ capl capll.pdf;jsessionid=E62ED1C6C5DB 9CE0CC9D44D257E38DFA?sequence $=1$

Harris, D. R. (1978). Settling Down: An Evolutionary Model for the Transformation of Mobile Bands into Sedentary Communities. En: Friedman, J. y Rowlands, M. J. (eds.). The Evolution of Social Systems. Proceedings of a Meeting of the Research Seminar in Archaeology and Related Subjects, held at the Institute of Archaeology, London University. Pittsburgh: University of Pittsburgh Press, pp. 401-417.

Quesada, J. M. (1998a). La caza en la Prehistoria. Madrid: Arco Libros.
Mammalian Faunas from Paleolithic Mammalian Faunas from Paleolithic 
Quesada, J. M. (1998b). Los cazadoresrecolectores cantábricos del Inter Laugerie-Lascaux. Complutum, 8, pp. 7-32.

Ramos, J. (1999): Europa prehistórica. Cazadores y recolectores. Madrid: Sílex.

Rasilla Vives, M. de la y Straus, L. G. (2004). El poblamiento en la región cantábrica en torno al Último Máximo Glacial:
Gravetiense y Solutrense. En: Fano, M. A. (coord.). Las Sociedades del Paleolitico en la Región Cantábrica. Kobie, 8 , pp. 209-244.

Straus, L. G. (1977). Of deerslayers and mountain men: Paleolithic faunal explotaition in Cantabrian Spain. En: Binford, L. R. (ed.). For Theory Building in
Archaeology. Essays on faunal remains, aquatic resources, spatial analysis, and systemic modeling. Nueva York: Academic Press, pp. 41-76.

Straus, L. G. (1983). El solutrense vascocantábrico. Una nueva perspectiva. Madrid: Ministerio de Educación, Cultura y Deporte. 